\title{
Dietary conjugated linoleic acid isomers and selenite or selenized yeast affect fatty acid concentration in the kidneys of rats*
}

\author{
M. Czauderna ${ }^{1}$, J. Kowalczyk, K.A. Krajewska \\ and A.J. Rozbicka-Wieczorek
}

\begin{abstract}
The Kielanowski Institute of Animal Physiology and Nutrition, Polish Academy of Sciences 05-110 Jabłonna, Poland
\end{abstract}

(Received 26 July 2011; revised version 1 August 2011; accepted 9 August 2011)

\begin{abstract}
The influence of diets enriched in a mixture of conjugated linoleic acid (CLA) isomers (CLAmix) and/or selenium as $\mathrm{Na}_{2} \mathrm{SeO}_{3}(\mathrm{SeIV})$ or selenized yeast ( $\mathrm{SeY}$ ) on feed intake, kidneys' weight and the concentrations of fatty acids (FA) in the kidneys of rats was investigated. The study was performed on 80 female Wistar rats (Hsd Brl Han: WIST), 8 weeks of age with an initial body weight of $195.7 \pm 0.8$ g. Each group numbered 8 rats. During the 7-day preliminary period the rats were fed a standard Labofeed $\mathrm{H}$ diet at a sub-maintenance level. Next, for 6 weeks the rats were fed ad libitum on the experimental diets supplemented with CLAmix, $0.2 \mathrm{ppm}$ Se or $0.5 \mathrm{ppm}$ Se as SeIV ( ${ }_{\mathrm{L}} \mathrm{SeIV}$ or ${ }_{\mathrm{H}} \mathrm{SeIV}$, respectively) and $\mathrm{SeY}\left({ }_{\mathrm{L}} \mathrm{SeY}\right.$ or ${ }_{\mathrm{H}} \mathrm{SeY}$, respectively). The rats were sacrificed at the end of the six-week experimental period. The diets enriched in CLAmix or Se (as SeIV or SeY) showed a negligible effect on kidneys' weight, although the diets containing simultaneously CLAmix and Se numerically increased kidneys' weight compared with the control animals. The addition of CLAmix to the diet, regardless of the higher level of SeY, showed a tendency to decrease in feed intake and decreased the concentrations of saturated (SFA), mono- (MUFA) and polyunsaturated (PUFA) fatty acids in comparison with the control rats. Dietary SeIV or SeY, irrespective of the concentration of extra Se, decreased the concentration of unsaturated fatty acids (UFA) and the sum of all assayed fatty acids ( $\Sigma F A)$ in the kidneys. The diet containing CLAmix and Se as ${ }_{\mathrm{H}} \mathrm{SeIV}$ or ${ }_{\mathrm{L}} \mathrm{SeY}$ decreased the concentrations of SFA, MUFA and PUFA in the kidneys compared with the control rats. On the other hand, the addition of ${ }_{\mathrm{L}} \mathrm{SeIV}$ or, especially, ${ }_{\mathrm{H}} \mathrm{SeY}$ to the diet enriched in CLAmix resulted in an increasing in the concentrations of SFA, MUFA and PUFA in the kidneys compared with the control group and rats fed the diets containing CLAmix, SeIV or SeY. The diet enriched in CLAmix and HSeY most effectively stimulated the accumulation of CLA isomers with the exception of cis11trans13CLA in the kidneys in comparison with other diets. Dietary CLAmix decreased the
\end{abstract}

\footnotetext{
* Supported in part by the Ministry of Science and Information Technology, Grant No. N N311 336433

${ }^{1}$ Corresponding author: e-mail: m.czauderna@ifzz.pan.pl
} 
capacity of $\Delta 9$-desaturase in the kidneys compared with the control rats. The addition of SeIV or $\mathrm{SeY}$ to the diet increased the capacity of $\Delta 4$-desaturase, while the diet containing CLAmix with or without Se as SeIV or SeY increased the capacity of $\Delta 4$ - and $\Delta 5$-desaturase in the kidneys compared with rats fed the diet with extra Se or the control diet. The present studies documented that dietary CLAmix resulted in decreasing in biosynthesis of fatty acids in the kidneys, while the diet with CLAmix and ${ }_{\mathrm{H}} \mathrm{SeY}$ most significantly stimulated the accumulation of SFA, MUFA and PUFA and long-chain PUFAn-3 and PUFAn-6 in the kidneys.

KEY WORDS: rats, kidneys, selenium, conjugated linoleic acid isomers, fatty acids

\section{INTRODUCTION}

The kidneys serve the body as a natural filter of the blood, and remove wastes which are diverted to the urinary bladder. In producing urine, the kidneys excrete wastes such as urea and ammonium; the kidneys also are responsible for the reabsorption of water, glucose and amino acids (Walter, 2004). The kidneys also produce hormones including calcitrol, renin and erythropoietin. The kidneys receive blood from the renal arteries, right and left, which branch directly from the abdominal aorta. Despite their relatively small size, the kidneys receive approximately $20 \%$ of the cardiac output (Al-kahtani et al., 2004).

Considering the above, it is reasonable to hypothesize that some additives to diets revealed influence on the concentration of physiologically important fatty acids (FA) in the kidney tissue. In our recent studies we found the influence of dietary conjugated linoleic acid (CLA) isomers or selected Se compounds on the accumulation of fatty acids and amino acids in the liver, pancreas, spleen, brain adipose tissues and muscles of rats (Czauderna et al., 2007, 2010a,b,c). Indeed, the addition of CLA isomers to rats' diets reduced body fat accretion, cholesterol ester synthesis and hepatocytic apolipoprotein B secretion (Javadi et at., 2007; Park, 2009). CLA isomers' influence on body fat reduction is suggested to be the result of multiple mechanisms: by reducing lipid accumulation in adipose tissues and/or adipocytes differentiation, by increasing energy expenditure, by increasing adipocyte apoptosis, by modulating adipokines and cytokines, such as leptin, TNF-a, adiponectin, or interleukins, and by stimulating FA $\beta$-oxidation in muscles (Park and Pariza, 2007).

Similarly, Se has been established as an essential microelement that is important in many biochemical and physiological processes (Wysocka et al., 2003; NavarroAlarcon and Cabrera-Vique, 2008). Se exerts its biological effect through several selenoproteins of which there may be more than 30 in mammalian systems. In general, selenoproteins serve as enzymes that catalyse redox reactions (Han et al., 2009). Examples are the glutathione peroxidases (GPx) which protect against oxidative stress. Specifically, Se-dependent GPx enzyme recycles glutathione, 
reducing lipid peroxidation by catalysing the reduction of peroxides, including hydrogen peroxide (Navarro-Alarcon and Cabrera-Vique, 2008; Navas-Acien et al., 2008). Our early studies using rats found that the level of CLA isomers and other polyunsaturated fatty acids (PUFA) in a liver or femoral muscles was positively correlated with the selenite (SeIV), selenate or selenized yeast (SeY) content in diets (Czauderna et al., 2004, 2011). So, we hypothesized that dietary SeIV or SeY increased concentrations of CLA isomers and other PUFA in the kidneys of rats. Indeed, these fatty acids (FA) are components of membranes of kidney cells. Therefore, this paper's objective was to evaluate the impact of different chemical forms and amounts of SeIV or SeY added to a diet enriched with CLA isomers (CLAmix) on the fatty acid (FA) profile in kidneys of rats.

\section{MATERIAL AND METHODS}

\section{Animals, housing, diets, experimental design and sampling}

The experiment was carried out on 80 female rats (Wistar, Hsd Brl Han: WIST), 8 weeks of age and with an initial body weight of about $195.7 \pm 0.8 \mathrm{~g}$. The animals were housed and handled in accordance with protocols approved by the Local Animal Care and Use Committee. The animals were housed individually in plastic cages at a temperature of $22 \pm 1^{\circ} \mathrm{C}$ with a $12 \mathrm{~h}$ light-dark cycle and relative humidity of $50-60 \%$. Each group comprised eight rats. The rats were fed the standard Labofeed $\mathrm{H}$ diet produced by the Feeds and Concentrates Production Plant in Kcynia (Poland), according to ISO 9001 Standards since 1998 (Czauderna et al., 2010a). For the current study, the standard Labofeed $\mathrm{H}$ diet was enriched in $0.2 \mu \mathrm{g} \mathrm{Se} / \mathrm{g}$ diet as selenite (Table 1). During the 7-day preliminary period the rats were fed a standard Labofeed $\mathrm{H}$ diet offered at sub-maintenance level $(9 \mathrm{~g}$ per day per rat) to reduce the rats' body fat; the average body weight of individually adapted rats was $179.0 \pm 6.1 \mathrm{~g}$ (Table 2). Next, the rats were fed ad libitum for 6 weeks the experimental diets supplemented with 1.5\% CLA isomer mixture (CLAmix), $0.2 \mu \mathrm{g} \mathrm{Se} /\left(\mathrm{g}\right.$ diet) $\left({ }_{\mathrm{L}} \mathrm{Se}\right)$ or $0.5 \mu \mathrm{g} \mathrm{Se} /\left(\mathrm{g}\right.$ diet) $\left.{ }_{\mathrm{H}} \mathrm{Se}\right)$ as selenite $\left({ }_{\mathrm{L}} \mathrm{SeIV}\right.$ and ${ }_{\mathrm{H}} \mathrm{SeIV}$ ) or selenized yeast $\left({ }_{\mathrm{L}} \mathrm{SeY}\right.$ and ${ }_{\mathrm{H}} \mathrm{SeY}$ ) (Table 2 ). Feed intake and body weight of rats were measured weekly. The rats were killed at the end of the six week experiment. The kidneys were removed, weighed and frozen. All kidneys were analysed individually. The concentrations of all assayed FA were calculated based on freeze-dried kidneys samples.

\section{Reagents, chemicals and analytical methods}

All chemicals were of analytical grade and organic solvents were of HPLC 
or GC grade. Dichloromethane (HPLC grade), $\mathrm{KOH}, \mathrm{NaOH}, \mathrm{Na}_{2} \mathrm{SO}_{4}$, chloroform and conc. $\mathrm{HCl}$ were purchased from $\mathrm{POCH}$ (Gliwice, Poland). Methanol (HPLC grade) and n-heptane (99\%, GC) were supplied by Lab-Scan (Ireland),

Table 1. Chemical composition and energy content of the basal $\operatorname{diet}^{1}$ and the selenized yeast (SeY)

\begin{tabular}{|c|c|}
\hline \multicolumn{2}{|l|}{$\begin{array}{l}\text { Item } \\
\text { Composition of the hasal diet }{ }^{2} \sigma / 100 \sigma \text { diet }\end{array}$} \\
\hline $\begin{array}{l}\text { Composition of the basal diet }{ }^{2}, \mathrm{~g} / 100 \mathrm{~g} \text { diet } \\
\text { dry matter } \\
\text { crude protein } \\
\text { lysine } \\
\text { methionine and cysteine } \\
\text { tryptophan } \\
\text { threonine } \\
\text { crude fibre } \\
\text { crude fat } \\
\text { ash } \\
\mathrm{N} \text { total } \\
\mathrm{N} \text { protein } \\
\mathrm{P} \text { total } \\
\text { mono-carbohydrates } \\
\text { starch } \\
\text { metabolizeable energy }{ }^{4}, \mathrm{MJ} / \mathrm{kg}\end{array}$ & $\begin{array}{l}88.2 \pm 0.9 \\
21.8 \pm 1.3 \\
1.31 \\
0.76 \\
0.28 \\
0.87 \\
3.85 \\
3.0 \pm 0.8 \\
5.9 \pm 0.6 \\
3.77 \\
3.17 \\
0.75 \\
5.75 \\
30.3 \\
13.9\end{array}$ \\
\hline $\begin{array}{l}\text { Composition of selenized yeast ( } \mathrm{SeY}) \\
\text { total Se, } \mathrm{mg} / \mathrm{g} \mathrm{DM} \\
\text { identified Se species, \% of total Se } \\
\text { selenomethionine, \% of total Se } \\
\text { Se-cysteine, \% of total Se } \\
\text { sodium selenite, \% of total Se } \\
\text { fatty acids, } \mathrm{mg} / \mathrm{g} \mathrm{DM}^{5}\end{array}$ & $\begin{array}{r}1.8 \\
88.3 \\
83.0 \\
5.0 \\
0.3\end{array}$ \\
\hline $\begin{array}{l}\mathrm{C} 16: 0 \\
\text { cis } 9 \mathrm{C} 16: 1 \\
\mathrm{C} 18: 0 \\
\text { cis } 9 \mathrm{C} 18: 1 \\
\text { cis } 11 \mathrm{C} 18: 1 \\
\text { cis9cis } 12 \mathrm{C} 18: 2 \text { (linoleic acid; LA) } \\
\text { cis } 9 \text { cis } 12 \text { cis } 15 \mathrm{C} 18: 3 \text { ( } \alpha \mathrm{LNA})\end{array}$ & $\begin{array}{r}9.0 \\
4.1 \\
13.6 \\
11.3 \\
0.8 \\
14.7 \\
0.16\end{array}$ \\
\hline 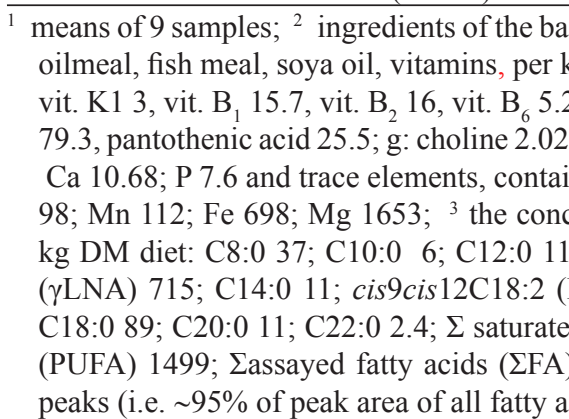 & $\begin{array}{l}\text { oat flakes, green meal, soyabean } \\
6 \text {, vit. } \mathrm{D}_{3} 2000 \text {; mg: vit. E } 86.1 \text {, } \\
\text { 2, folic acid } 3.03 \text {, nicotinic acid } \\
\text { er g DM diet; } \mathrm{mg}: \mathrm{Na} 3.6 ; \mathrm{K} 8.3 \text {; } \\
\text { as } \mathrm{Na}_{2} \mathrm{SeO}_{3} 0.2 ; \mathrm{Cu}-13.9 ; \mathrm{Zn} \\
\text { acids in the basal diet, mg per } \\
(\alpha \mathrm{LNA}) 8 ; \text { cis } 6 \text { cis } 9 \text { cis } 12 \mathrm{C} 18: 3 \\
\text { cis } 9 \mathrm{C} 18: 1187 ; \text { cis } 6 \mathrm{C} 18: 1112 \text {; } \\
7 \text {; } \Sigma \text { polyunsaturated fatty acids } \\
\text { m } 3 \text { samples; }{ }^{5} \text { main fatty acid } \\
\text { by GC-MS }\end{array}$ \\
\hline
\end{tabular}




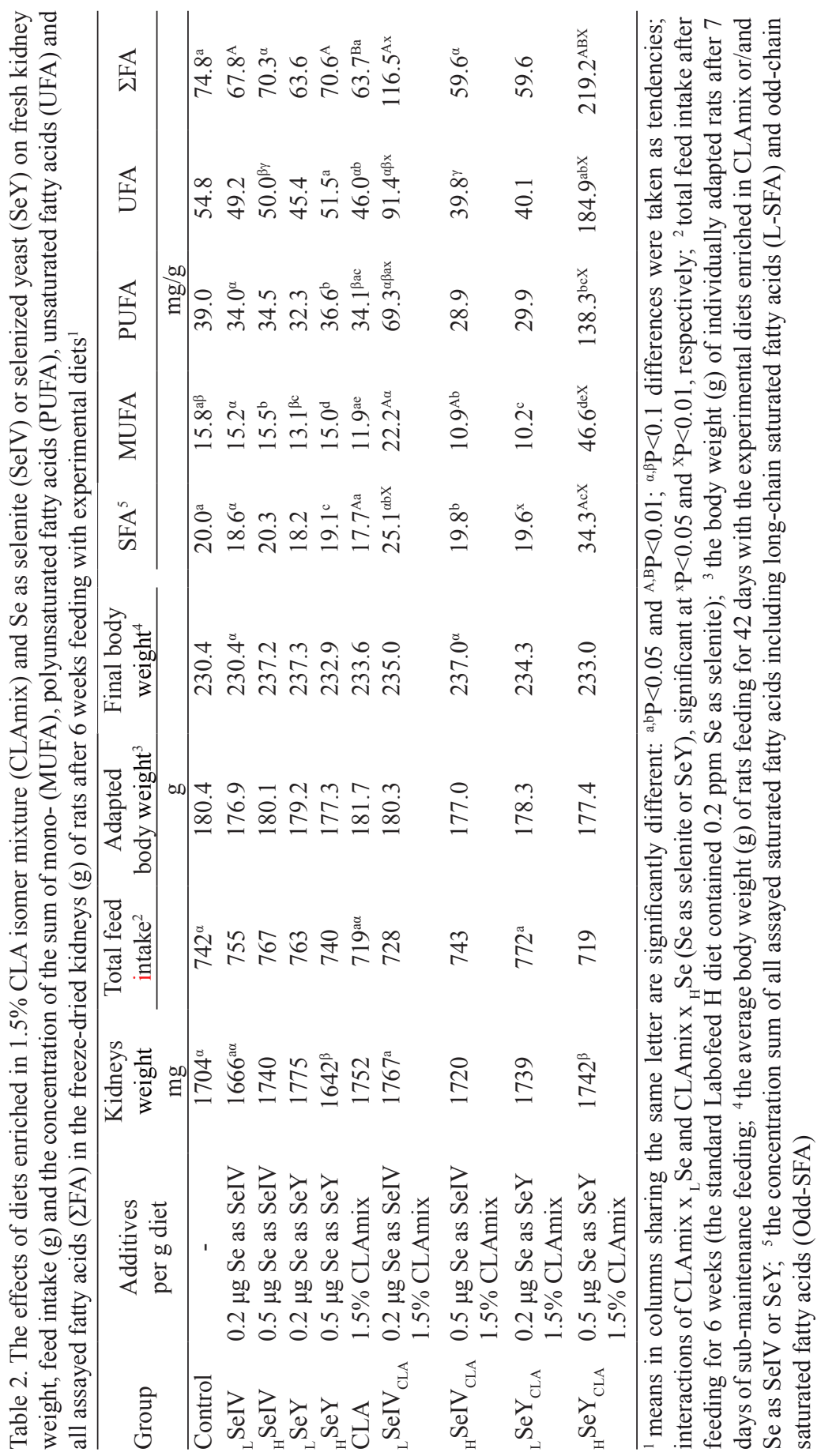


while the CLA isomer mixture (2.1\% ttCLA, 7.1\% c11t13CLA, 40.8\% $c 9 t 11$ CLA, $41.3 \% t 10 c 12 \mathrm{CLA}, 6.7 \% c 8 t 10 \mathrm{CLA}$ and $2.0 \% c c \mathrm{CLA} ; t$ and $c$ -abbreviations for trans and cis) by Industrial Chemistry Research Institute (Warsaw, Poland). The concentration ratio $\left(\mathrm{R}_{c \mid t 1 l \text { CLA } t 10 c 12 \mathrm{CLA}}\right)$ of $c 9 t 11 \mathrm{CLA}$ to t10c12CLA in the dietary CLA isomer mixture was 0.988 . The selenized yeast (Se-Saccharomyces cerevisiae) was donated by Sel-Plex (non-commercial yeast sample; Alltech Inc., USA). About $83 \%$ of the total selenium content of the selenized yeast $(\mathrm{SeY})$ represents $\mathrm{Se}$ in the form of seleno-methionine (Se-Met) incorporated into the proteins of Saccharomyces cerevisiae (Table 1) (Wysocka et al., 2003; Rayman, 2004; Weiss and Hogan, 2005). Fatty acid methyl ester (FAME) standards, $25 \% \mathrm{BF}_{3}$ in methanol and sodium selenite were purchased from Supelco and Sigma (USA). Water used for the preparation of mobile phases and chemical reagents was prepared using an Elix $^{\mathrm{TM}}$ water purification system (Millipore). The mobile phases were filtered through a $0.45 \mu \mathrm{m}$ membrane filter (Millipore).

All of the fatty acid standards and reagents, saponification and FA methylation methods were as described previously (Czauderna et al., 2009).

\section{Chromatographic equipment}

The analyses of all FAME in processed kidneys samples were performed on a SHIMADZU GC-MS-QP2010 Plus EI equipped with a BPX70 fused silica capillary column $(120 \mathrm{~m} \times 0.25 \mathrm{~mm}$ i.d. $\times 0.25 \mu \mathrm{m}$ film thickness; SHIM-POL $)$, quadrupole mass selective (MS) detector (Model 5973N) and injection port. Helium as the carrier gas operated at a constant pressure $(223.4 \mathrm{kPa})$ and flow rate of $1 \mathrm{ml} / \mathrm{min}$. Injector and MS detector temperatures were maintained at 200 and $240^{\circ} \mathrm{C}$, respectively. The total FAME profile in a one $\mu 1$ sample at a split ratio of 10:1 was determined using the column temperature gradient programme as previously described (Czauderna et al., 2009). FAME identification was validated based on electron impact ionization spectra of FAME and compared with authentic FAME standards and NIST 2007 reference weight spectra library.

\section{Statistical analysis}

Results are presented as means of 8 individually analysed kidneys samples. Mean values in columns having the same superscripts are significantly different at ${ }^{\mathrm{a}, \mathrm{b}} \mathrm{P}<0.05$ and ${ }^{\mathrm{A}, \mathrm{B}} \mathrm{P}<0.01$, while differences at ${ }^{\alpha, \beta} \mathrm{P}=0.1$ are indicated as tendencies. These one-factorial statistical analyses of the effects of SeY or the CLAmix in the diets were conducted using the non-parametric Mann-Whitney $U$ test for comparing independent experimental groups. Statistical analyses of interactions 
between CLAmix and Se as ${ }_{\mathrm{L}} \mathrm{SeIV},{ }_{\mathrm{H}} \mathrm{SeIV},{ }_{\mathrm{L}} \mathrm{SeY}$ or ${ }_{\mathrm{H}} \mathrm{SeY}$ (i.e. CLA $\times{ }_{\mathrm{L}} \mathrm{SeIV}, \mathrm{CLA}$ $\times{ }_{\mathrm{H}} \mathrm{SeIV}, \mathrm{CLA} \times{ }_{\mathrm{L}} \mathrm{SeY}$ and CLA $\times{ }_{\mathrm{H}} \mathrm{SeY}$ ) were performed using two factorial ANOVA analysis; the interactions were significant at the ${ }^{\mathrm{x}, \mathrm{P}} \mathrm{P}<0.05$ and ${ }^{\mathrm{X}, \mathrm{Y}} \mathrm{P}<0.01$ levels, respectively. Statistical analyses were performed using the Statistica v. 6 software package (2002; www.statsoft.pl).

\section{RESULTS AND DISCUSSION}

The effects of experimental diets on kidneys weight and feed intake. Mammalian kidneys have a dominant role in controlling both the concentration of body fluids and their volume. Fortunately, in the current study, no macroscopic lesions or pathological changes were found in the kidneys as well as in other internal organs of rats fed diets enriched in 1.5\% CLAmix regardless of the presence of Se as $\mathrm{SeIV}$ or SeY. Moreover, there was no negative influence on body weight of rats fed the diets enriched in the lower $(0.2 \mu \mathrm{g} \mathrm{Se} / \mathrm{g}$ diet $)$ and higher $(0.5 \mu \mathrm{g} \mathrm{Se} / \mathrm{g}$ diet) levels of Se regardless of the chemical form of added Se compounds (Table 2). Indeed, signs of selenosis were observed for diets containing $\sim 5 \mu \mathrm{g}$ Se per $\mathrm{g}$ diets, which is a level $\sim 100$ times the contribution of Se to typical mammal diets (Navarro-Alarcon and Cabrera-Vique, 2008). Only chronic feeding of inorganic Se compounds at a rate of more than $5 \mu \mathrm{g}$ Se per g diets can be hepatotoxic and teratogenic in animals and humans (Tapiero et al., 2003). Moreover, our previous studies documented that only $2 \mu \mathrm{g}$ Se as selenite per g diets decreased the body weight of rats, although no macroscopic lesions and toxic symptoms of this diet were observed in rats fed this diet (Czauderna et al., 2003, 2004).

As can be seen from the results summarized in Table 2, the addition of CLAmix to the diets, irrespective of the presence of extra Se as SeIV or SeY, increased the kidneys' weight in comparison with the control group, although these differences were no statistically significant. Concomitantly, these diets increased also the body weight gain (BWG) of rats (Czauderna et al., 2010a). Interestingly, the diets containing ${ }_{\mathrm{L}} \mathrm{SeIV}$ or ${ }_{\mathrm{H}} \mathrm{SeY}$ numerically decreased the weight of kidneys compared with the control rats; moreover, the diets enriched in SeIV or SeY, regardless of the concentration of extra Se, also resulted in a decreasing in the weight of the brain, liver and spleen of examined animals compared with the control group, while the diets containing SeY or SeIV (i.e. ${ }_{\mathrm{L}} \mathrm{SeY},{ }_{\mathrm{H}} \mathrm{SeY}$ and especially ${ }_{\mathrm{H}} \mathrm{SeIV}$ ) increased BWG of rats (Czauderna et al., 2009, 2010a,b,c). Therefore, we suggest that dietary SeIV or SeY revealed specific effects on some internal organs of rats. The addition of CLAmix to the diet, regardless of the higher level of SeY, showed a tendency to decrease in feed intake in comparison with the control rats (Table 2). On the other hand, other experimental diets resulted in inconsistently small changes in feed intake compared with the control group. 
The effects of experimental diets on concentrations of saturated and monounsaturated fatty acids in the kidneys. It was found that supplementation of the diet enriched in CLAmix decreased $(\mathrm{P}<0.05)$ the concentration sum of saturated (SFA) and monounsaturated (MUFA) fatty acids in the kidneys compared with the control group (Table 2). Moreover, detailed analysis of above results documented that dietary CLAmix decreased $(\mathrm{P}<0.05)$ the concentration of myristic acid $(\mathrm{C} 14: 0$; Table 3), the sum of atherogenic (A-SFA), thrombogenic (T-SFA) SFA (Ulbricht and Southgate, 1991) (Table 4) as well as long-chain (L-SFA) and odd (Odd-SFA) SFA in the kidneys (Table 5). Moreover, the serious decrease in the concentrations of mono- and polyunsaturated FA in the kidneys (Table 2) explains higher values of atherogenic $\left(\mathrm{A}_{\text {index }}\right)$ and thrombogenic $\left(\mathrm{T}_{\text {index }}\right)$ indexes in the kidneys than in the control group (Table 4). The diet enriched in 1.5\% CLAmix had a similar effect on the concentrations of A-SFA and T-SFA in the brain, spleen, femoral muscles and abdominal fat of rats (Czauderna et al., 2009, 2010a,c). Thus, our current results are consistent with studies of Alasnier et al. (2002), Bauman et al. (2003) and Czauderna et al. (2004) in which diets supplemented with CLA isomers increased FA $\beta$-oxidation in the fat pad and skeletal muscles but not in the liver of mice and rats. The addition of the lower amount of SeIV or SeY to the diet resulted in a numerically decreasing in the concentrations of SFA, A-SFA, T-SFA, L-SFA and MUFA, including trans-FA (t11C18:1), in the kidneys compared with the control group (Tables 2-5). Considering the above, we suggest that the lower amount of SeIV or SeY, like CLAmix, in the diet stimulated SFA $\beta$-oxidation in the kidneys.

On the other hand, the accumulation of saturated fatty acids in the kidneys stimulated the addition of CLAmix to the diet enriched in ${ }_{\mathrm{L}} \mathrm{SeIV}$ or ${ }_{\mathrm{H}} \mathrm{SeY}$; there are statistically significant CLAmix $\times{ }_{L} \mathrm{SeIV}$ and CLAmix $\times{ }_{H} \mathrm{SeY}$ interactions $(\mathrm{P}<0.01)$ on the concentration of SFA in the kidneys. There are also the statistically significant CLAmix $\times{ }_{\mathrm{H}} \mathrm{SeY}$ interactions on the concentrations of L-SFA, Odd-SFA, MUFA and $c 9 \mathrm{C} 18: 1$ in the kidneys (Tables 3 and 5). Thus, it can be concluded that the simultaneous addition of CLAmix and ${ }_{\mathrm{H}} \mathrm{SeY}$ to the diet stimulated elongation of fatty acids and decreased the $\beta$-oxidation of fatty acids in the kidneys. In consequence, the concentrations of all assayed FA ( $\Sigma F A)$, including long-chain polyunsaturated fatty acids (LPUFA) and L-SFA (Tables 2, 4 and 5), increased in the kidneys of rats fed the diet containing CLAmix and ${ }_{\mathrm{H}} \mathrm{SeY}$. Interestingly, the significant increase in the concentrations of mono- and polyunsaturated FA in the kidneys explains lower values of $\mathrm{A}_{\text {index }}$ and $\mathrm{T}_{\text {index }}$ in the kidneys of rats fed the diets containing CLAmix and ${ }_{\mathrm{H}} \mathrm{SeY}$ in comparison with the control group (Table 4). Similarly, the simultaneous addition of CLAmix and selenate to the rats' diet resulted in increasing in the concentration of $\Sigma F A$ in the kidneys, pancreas, heart, femoral muscles, abdominal fat and blood plasma (Czauderna et al., 2003, 2004; Niedźwiedzka et al., 2006). Moreover, the diet enriched in CLAmix and 


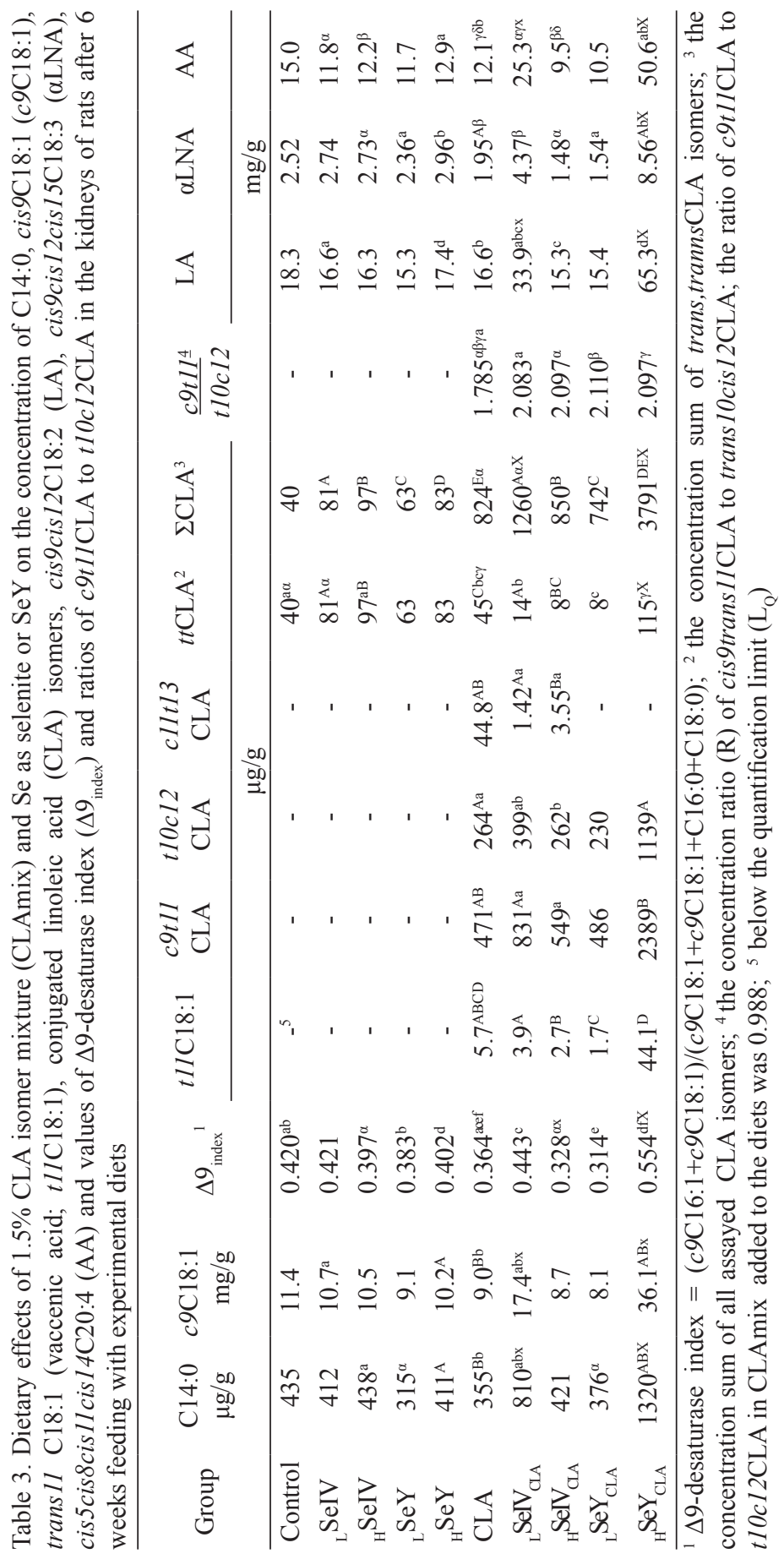




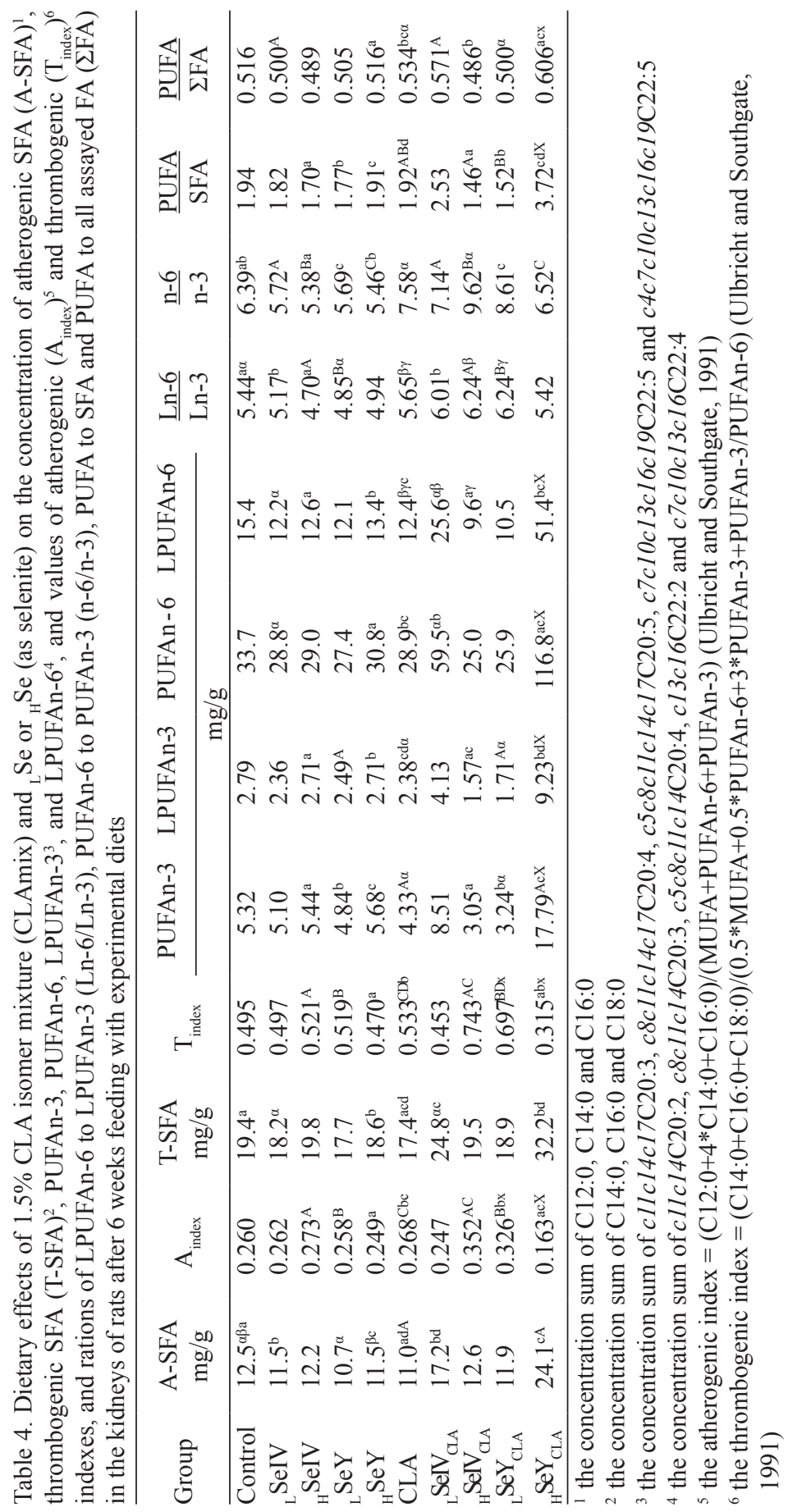




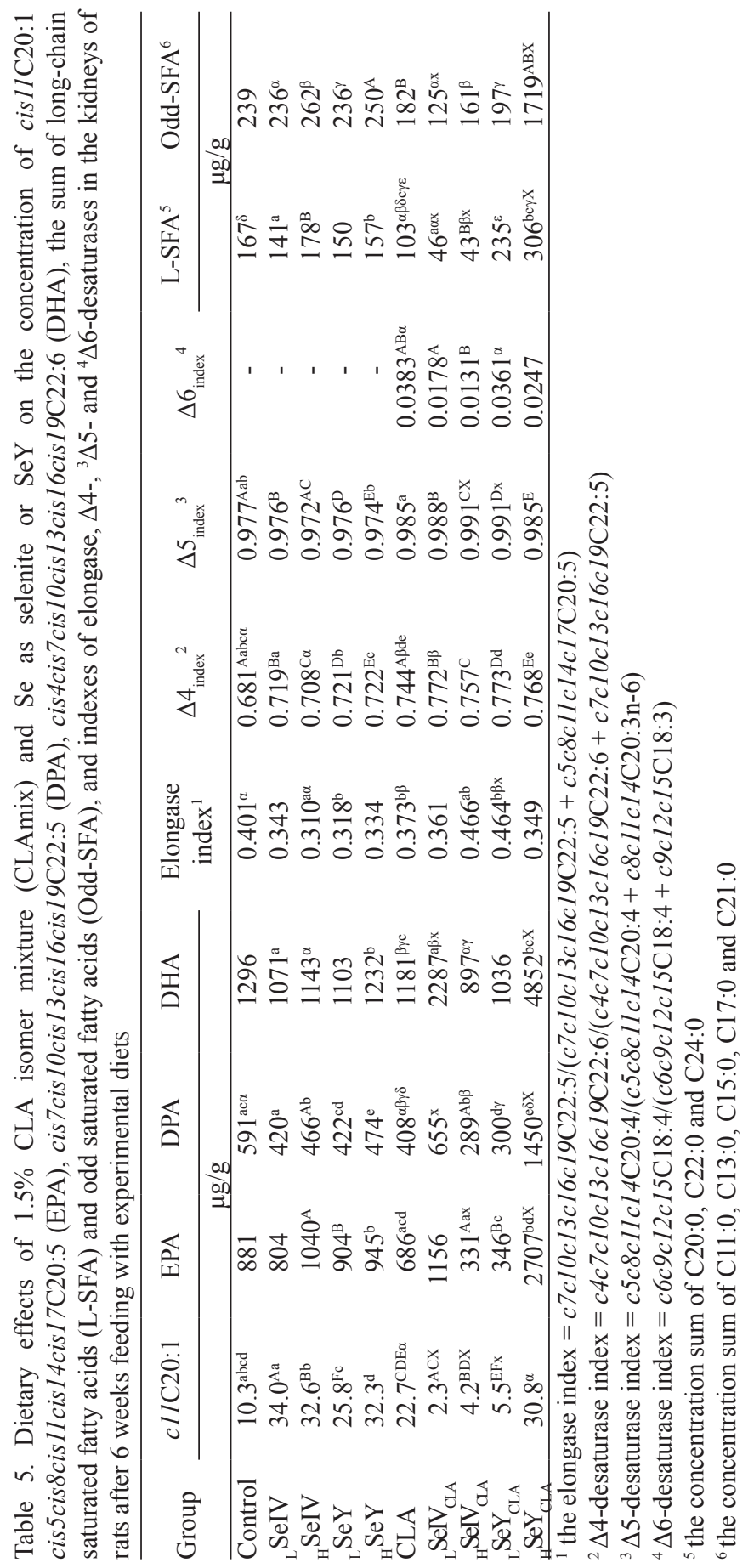


${ }_{\mathrm{H}} \mathrm{SeY}$ also stimulated accumulation of $\Sigma \mathrm{FA}$ in the liver, pancreas, blood plasma and abdominal fat of rats in comparison with the control group (Czauderna et al., 2007, 2009, 2010a,b,c, 2011).

Recent investigations (Alasnier et al., 2002; Bauman et al., 2003; Czauderna et al., 2004) have found that after CLA isomers (especially t10c12CLA) were fed to rats or mice, the content of stearyl-CoA desaturase gene $1 \mathrm{mRNA}$ in the liver decreased by $45-75 \%$. Therefore, a decrease in $\Delta 9$-desaturation is a major reason for modification of monounsaturated fatty acids, especially $c 9 \mathrm{C} 18: 1$, in animals fed diets enriched in CLA isomers (Tables 2 and 3). The substrate: product relationship for $\Delta 9$-desaturase is further supported by detailed analysis of values of the $\Delta 9$-desaturase index (Table 3). Interestingly, the diets enriched in SeIV or SeY also numerically decreased the concentration of $c 9 \mathrm{C} 18: 1$ and usually MUFA and values of the $\Delta 9$-desaturase index in the kidneys. Similarly, diets enriched in SeIV or SeY also decreased the concentration of $c 9 \mathrm{C} 18: 1$ and values of $\Delta 9$-desaturase index in the liver, femoral muscles, brain, pancreas and abdominal fat of examined rats (Czauderna et al., 2007, 2009, 2010a,b,c, 2011). Moreover, our recent investigation documented that a diet enriched in selenate ( $2 \mu \mathrm{g} \mathrm{Se} / \mathrm{g}$ diet) also decreased the concentration of $c 9 \mathrm{C} 18: 1$ and the value of $\Delta 9$-desaturase index in the liver, kidneys, femoral muscles and spleen of rats (Czauderna et al., 2004). Surprisingly, the addition of CLAmix to the diet enriched in the higher concentration of SeY significantly stimulated the accumulation of MUFA, including especially $c 9 \mathrm{C} 18: 1$ and $c 9 \mathrm{C} 16: 1$, in the kidneys in comparison with the control group. Indeed, the yield of $\Delta 9$-desaturation as well as the value of $\Delta 9$-desaturase index significantly increased in the kidneys of rats fed the diet enriched in CLAmix and ${ }_{\mathrm{H}} \mathrm{SeY}$; there are the statistically significant interactions at $\mathrm{P}<0.01$ (Tables 2 and 3). Similarly, the diet containing CLAmix and Se as $\mathrm{SeY}$ or SeIV (regardless of their concentration) increased the accumulation of c9C18:1 as well as MUFA in the abdominal fat (Czauderna et al., 2010a) and blood plasma (Czauderna et al., 2010c) in comparison with the control group or rats fed the diet enriched in SeIV or SeY. Thus, the current study and our previous studies documented that simultaneously dietary CLAmix and ${ }_{\mathrm{H}} \mathrm{SeY}$ (the positive interaction) most efficiently stimulated the $\Delta 9$-desaturation in the kidneys as well as in abdominal fat and plasma of rats (Czauderna et al., 2010a,c).

The effect of experimental diets on concentrations of CLA isomers in the kidneys. The experimental results regarding the concentration of additives in the diets as well as the influence of the examined diets on the concentration of CLA isomers in the kidneys of rats are summarized in Table 3. As expected, the addition of CLAmix to diets, regardless of the presence of SeIV or SeY, resulted in an increasing in concentrations of c9t11CLA, t10c12CLA, c9t13CLA and $t t$ CLA in the kidneys in comparison with the control rats or rats fed the diets 
containing only extra SeIV or SeY. The diets containing CLAmix and Se as SeIV or SeY statistically significantly $(\mathrm{P}<0.01)$ increased the concentration of the sum of all assayed CLA isomers ( $\Sigma C L A)$ in the kidneys compared with the control rats or rats fed the diets with ${ }_{\mathrm{L}} \mathrm{SeIV},{ }_{\mathrm{H}} \mathrm{SeIV},{ }_{\mathrm{L}} \mathrm{SeY}$ or ${ }_{\mathrm{H}} \mathrm{SeY}$ (Table 3). Thus, the current results support our recent studies, in which dietary CLAmix, irrespective of presence of selenate, SeIV or SeY, significantly $(\mathrm{P}<0.01)$ increased the concentration of CLA isomers in femoral muscles and internal organs of rats (Czauderna et al., 2003, 2004, 2007, 2009, 2010a,b,c, 2011; Niedźwiedzka et al., 2006). Detailed analysis of these results revealed that the addition of ${ }_{\mathrm{H}} \mathrm{SeY}$ to the diet containing CLAmix statistically significantly increased the concentration of $c 9 t 11 \mathrm{CLA}, t 10 c 12 \mathrm{CLA}, t t \mathrm{CLA}$ and $\Sigma \mathrm{CLA}$ in the kidneys compared with rats fed the diet with CLAmix $(\mathrm{P}<0.01)$, as well as rats fed the diets containing CLAmix and $\mathrm{Se}$ as ${ }_{\mathrm{L}} \mathrm{SeIV},{ }_{\mathrm{H}} \mathrm{SeIV}$ or ${ }_{\mathrm{L}} \mathrm{SeY}$. Similarly, the diet enriched in CLAmix and ${ }_{\mathrm{L}} \mathrm{SeIV}$ increased the concentration of $c 9 t 11 \mathrm{CLA}, t 10 c 12 \mathrm{CLA}$ and $\Sigma \mathrm{CLA}$ in the kidneys compared with rats fed the diet enriched only in CLAmix. On the other hand, the addition of ${ }_{\mathrm{H}} \mathrm{SeIV}$ or ${ }_{\mathrm{L}} \mathrm{SeY}$ to the diet containing CLAmix usually numerically decreased the concentration of CLA isomers in the kidneys in comparison with rats fed the diet with CLAmix. Interestingly, the addition SeIV or SeY to the diet containing CLAmix statistically significantly $(\mathrm{P}<0.01)$ reduced the accumulation of c11t13CLA in the kidneys compared with rats fed the diet with only CLAmix. Surprisingly, $t \mathrm{CLA}$ isomers are detected in the kidneys of rats fed the control diet as well as the diets containing Se as SeIV or SeY. These results suggest that examined rats practice coprophagia as bacteria in rats' large-intestine can produce $t t$ CLA isomers. Thus, our current results are in agreement with our previous studies which also revealed that CLA isomers were quantitatively detected in femoral muscles and perigonadal fat of rats fed a control diet, i.e. without CLA isomers (Czauderna et al., 2003). Interestingly, the diets enriched in SeIV or $\mathrm{SeY}$ numerically increased the accumulation of $t \mathrm{tCLA}$ isomers in the kidneys compared with the control group. On the other hand, the addition of CLAmix to the diets containing ${ }_{\mathrm{L}} \mathrm{SeIV},{ }_{\mathrm{H}} \mathrm{SeIV}$ or ${ }_{\mathrm{L}} \mathrm{SeY}$ revealed a competitive effect (a negative interaction) on the incorporation of $t$ CLA isomers in the kidneys. Consequently, these diets resulted in a decreasing in $t t$ CLA isomers in the kidneys compared with the control rats or rats fed the diets containing SeIV, SeY or CLAmix.

Detailed analysis of results documented that $t 10 \mathrm{c} 12 \mathrm{CLA}$ is faster metabolized in the kidneys than $c 9 t 11$ CLA. Therefore, the concentration ratio of $c 9 t 11$ CLA/ t10c12CLA in the kidneys of rats fed the diets enriched with the CLAmix were, regardless of the presence of SeIV or SeY, higher compared with the ratio $\left(\mathrm{R}_{c 9 t 1 l \mathrm{CLA}}\right.$, ${ }_{t 10 c / 2 \mathrm{CLA}}$ ) of these isomers in the CLA isomer mixture added to the diets (i.e. 1.785 -2.110 vs 0.988 ; Table 3 ). Thus, our current results are in agreement with results of Alasnier et al. (2002) and our previous investigations (Czauderna et al., 2003, 
$2004)$ in which the $t 10 c 12$ CLA and $t 10 t 12$ CLA were also more efficiently driven through $\beta$-oxidation in the cells of the liver, kidneys, adipose tissue or femoral muscles of rats than their 9,11 homologues of CLA. Moreover, our present studies documented that the addition of SeIV or SeY to the diet enriched in CLAmix increased the concentration ratio (R) of $c 9 t 11 \mathrm{CLA} / t 10 c 12 \mathrm{CLA}$ in the kidneys in comparison with the $\mathrm{R}_{c \text { ctllCLA } / 10 c 12 \mathrm{CLA}}$ value in the kidneys of rats fed the diet containing only CLAmix. Therefore, it can be concluded that interaction between CLAmix and Se as SeIV or SeY, irrespective of the concentration of extra dietary Se, increased the efficiency of $\beta$-oxidation of $t 10 c 12$ CLA and t10t12CLA in the kidneys. The current studies are in agreement with our previous investigation in which the diet containing CLAmix and Se as SeY or SeIV also increased (the positive interaction) the $\beta$-oxidation of $t 10 \mathrm{c} 12 \mathrm{CLA}$ in the liver, femoral muscles, spleen and abdominal fat of rats (Czauderna et al., 2009, 2010a,b,c, 2011). On the other hand, selenate (a stronger oxidant than selenite) added to the diet with CLAmix diminished the efficiency of $\beta$-oxidation of $t 10 c 12$ CLA and $t 10 t 12 \mathrm{CLA}$ in the kidneys, liver, plasma or femoral muscles of rats compared with rats fed the diet containing only CLAmix (Czauderna et al., 2003, 2004; Niedźwiedzka et al., 2006).

The effects of experimental diets on concentrations of polyunsaturated fatty acids in the kidneys. The present studies documented that the addition of CLAmix and/or Se as SeIV or SeY to the diet had significant effect on concentrations of PUFA in the kidneys of rats. Indeed, as can be seen from results summarized in Tables 3, 4 and 5, the diet enriched in CLAmix numerically decreased the concentrations of $c 9 c 12 \mathrm{C} 18: 2$ (LA), $c 9 c 12 c 15 \mathrm{C} 18: 3$ ( $\alpha \mathrm{LNA}$ ), $c 5 c 8 c 11 c 14 \mathrm{C} 20: 4$ (AA), $c 5 c 8 c 11 c 14 c 17 \mathrm{C} 20: 5$ (EPA), $c 7 c 10 c 13 c 16 c 19 \mathrm{C} 22: 5$ (DPA) and $c 4 c 7 c 10 c 13 c 16 c 19 \mathrm{C} 22: 6$ (DHA) in the rats' kidneys. Furthermore, this additive in the rats' diet decreased the concentration sum of PUFA, PUFAn-3, LPUFAn-3, PUFAn-6 and LPUFAn-6 in the kidneys. Considering also the influence of dietary CLAmix on the concentration of SFA, MUFA, unsaturated FA (UFA) and $\Sigma$ FA (Table 2), we argue that the CLAmix added to the rats' diet stimulated the $\beta$-oxidation of saturated and unsaturated fatty acids in the rats' kidneys. Indeed, our recent studies also indicate that feeding the CLA isomers resulted in enlargement of the liver (Czauderna et al., 2003). At the peroxisomal level, considerable proliferation of small peroxisomes takes place together with increased capacity for $\beta$-oxidation of long-chain FA; at the mitochondrial level, a greater part of activated fatty acids in animals' body was directed from triacylglycerol esterification towards oxidation (Alasnier et al., 2003). According to the above, our detailed investigations also demonstrated that the addition of CLAmix to the diet decreased the value of the elongase index in the kidneys and pancreas (Czauderna et al., 2010b) in comparison with the control rats (Table 5). Unexpectedly, dietary CLAmix numerically increased values of the ratio of 
LPUFAn-6/LPUFAn-3 and PUFAn-6/PUFAn-3 in the kidneys (Table 5) as well as in the liver, spleen and blood plasma (Czauderna et al., 2010c, 2011). Moreover, the addition of SeIV or SeY to the diet containing CLAmix usually increased the values of these ratios in the kidneys compared with rats fed the diet containing only CLAmix. Considering the above, we suggest that the addition of CLAmix to the rats' diet preferentially stimulated the accumulation of polyunsaturated FA n-6 and, probably, the catabolism of polyunsaturated FA n-3 in the kidneys.

On the other hand, the addition of ${ }_{\mathrm{L}} \mathrm{SeIV}$ or ${ }_{\mathrm{H}} \mathrm{SeY}$ to the diet enriched in CLAmix stimulated the accumulation of LA, $\alpha$ LNA, AA, EPA, DPA and DHA in the rats' kidneys, pancreas (Czauderna et al., 2010b) and blood plasma (Czauderna et al., 2010c) in comparison with rats fed the diet containing the single additive as well as the control rats. Accordingly, these diets increased also the concentration sum of PUFA, PUFAn-3, LPUFAn-3, PUFAn-6, LPUFAn-6 as well as the ratio of PUFA/SFA and PUFA/ $\Sigma$ FA in the kidneys; there are statistically significant CLAmix $x{ }_{H} \mathrm{SeY}$ interaction effect $(\mathrm{P}<0.01)$ on the concentrations of these fatty acids in the kidneys (Tables 2-5) and liver (Czauderna et al., 2011).

The addition of SeIV or SeY to the diet, regardless of the concentration of extra SeIV or SeY, decreased the ratio of PUFAn-6/PUFAn-3 and LPUFAn-6/ LPUFAn-3 in the kidneys, liver (Czauderna et al., 2009, 2011), pancreas (Czauderna et al., 2010b) and blood plasma (Czauderna et al., 2010c) compared with the control rats. Considering the above, we argued that dietary SeIV or SeY more effectively stimulated the catabolism of PUFAn- 6 and LPUFAn- 6 than PUFAn-3 and LPUFAn-3 in these tissues of rats. As can be seen from results summarized in Table 5, dietary SeIV or SeY increased the yield of $\Delta 4$-desaturation in the kidneys and femoral muscles (Czauderna et al., 2009, 2011) compared with the control group. On the other hand, these dietary additives decreased the yield of $\Delta 5$-desaturation in the kidneys, while the simultaneous addition of CLAmix and $\mathrm{Se}$ as SeIV or SeY lowered the capacity of this desaturase compared with rats fed the diet with only CLAmix. On the other hand, the addition of CLAmix to the diet enriched in SeIV or SeY enlarged the capacity of $\Delta 4$ - and $\Delta 5$-desaturases in the kidneys compared with rats fed the diet containing CLAmix, SeIV or SeY.

\section{CONCLUSIONS}

Diets containing selenite, selenized yeast (up to $0.5 \mathrm{mg}$ total dietary $\mathrm{Se} / \mathrm{kg}$ diet) and CLA isomers (up to $1.5 \%$ ) can be regularly used to increase the concentration of Se and CLA isomers in monogastric farm animals without adversely influencing performance. The results documented that the CLAmix and ${ }_{\mathrm{H}} \mathrm{SeY}$ treatment most significantly stimulated the accumulation of saturated, mono- and polyunsaturated 
fatty acids in the kidneys of rats. In accordance with physiological properties of CLA isomers, CLAmix added to the rats' diet resulted in the decreasing in biosynthesis of fatty acids in this internal organ.

\section{REFERENCES}

Alasnier C., Berdeaux O., Chardigny J.M., Sébédio J.L., 2002. Fatty acid composition and conjugated linoleic acid content of different tissues in rats fed individual conjugated linoleic acid isomers given as triacylglycerols. J. Nutr. Biochem. 13, 337-345

Al-kahtani M.A., Zuleta C., Caviedes-Vidal E., Garland T., 2004. Kidney mass and relative medullary thickness of rodents in relation to habitat, body size, and phylogeny. Physiol. Biochem. Zool. 77, 346-365

Bauman D.E., Corl B.A., Peterson D.G., 2003. The biology of conjugated linoleic acids in ruminants. In: J.L. Sebedio, W.W. Christie, R.O. Adlof (Editors). Advances in Conjugated Linoleic Acid Research. AOCS Press, Champaign, Illinois. Vol. II, pp. 146-173

Czauderna M., Kowalczyk J., Korniluk K., 2007. Effect of dietary conjugated linoleic acid mixture and selenized yeast on concentrations of selected fatty acids and mineral elements in rats. Arch. Anim. Nutr. 61, 135-150

Czauderna M., Kowalczyk J., Krajewska K.A., 2010b. The effect of conjugated linoleic acid isomers, selenite and selenized yeast supplemented to the diet on the fatty acid profile in the pancreas of rats. J. Anim. Feed Sci. 19, 495-508

Czauderna M., Kowalczyk J., Krajewska K.A., 2011. Influence of dietary selenium level on the concentration of conjugated linoleic acid isomers, other fatty acids and amino acids in the liver and femoral muscles of rats. Czech J. Anim. Sci. 56, 81-94

Czauderna M., Kowalczyk J., Krajewska K.A., Leng L'., 2010c. Selenite, selenized yeast, or conjugated linoleic acid isomers supplemented to the diet influence the fatty acid profile in the spleen and blood plasma of rats. J. Anim. Feed Sci. 19, 613-627

Czauderna M., Kowalczyk J., Krajewska K.A., Michalski J.P., 2010a. The dietary level of selenite and selenized yeast influences the concentrations of selected fatty acids in the abdominal fat and brain of rats. J. Anim. Feed Sci. 19, 113-129

Czauderna M., Kowalczyk J., Krajewska K.A., Rozbicka A.J., Michalski J., 2009. Dietary selenite and conjugated linoleic acid isomers influence fatty acid concentrations in the liver and femoral muscles of rats. J. Anim. Feed Sci. 18, 564-581

Czauderna M., Kowalczyk J., Niedźwiedzka K.M., Wąsowska I., Pastuszewska B., 2004. Conjugated linoleic acid (CLA) content and fatty acids composition of muscle in rats fed isomers of CLA and selenium. J. Anim. Feed Sci. 13, 183-196

Czauderna M., Kowalczyk J., Wąsowska I., Niedźwiedzka K.M., Pastuszewska B., 2003. The effects of selenium and conjugated linoleic acid (CLA) isomers on fatty acid composition, CLA isomer content in tissues, and growth of rats. J. Anim. Feed Sci. 12, 865-881

Han F., Chen D., Yu B., Luo W., 2009. Effects of different selenium sources and levels on serum biochemical parameters and tissue selenium retention in rats. Front. Agric. China 3, 221-225

Javadi M., Geelen M.J.H., Everts H., Lemmens A.G., Beynen A.C., 2007. Body composition and selected blood parameters in mice fed a combination of fibre and conjugated linoleicacid. J. Anim. Physiol. Anim. Nutr. 91, 492-497

Navarro-Alarcon M., Cabrera-Vique C., 2008. Selenium in food and the human body: A review. Sci. Total Envir. 400, 115-141 
Navas-Acien A., Bleys J., Guallar E., 2008. Selenium intake and cardiovascular risk: what is new? Curr. Opin. Lipidol. 19, 43-49

Niedźwiedzka K.M., Wąsowska I., Czauderna M., Kowalczyk J., Pastuszewska B., 2006. Influence of dietary conjugated linoleic acid isomers and Se on fatty acids profile in blood plasma and some tissues of rats. J. Anim. Feed Sci. 15, 471-489

Park Y., 2009. Conjugated linoleic acid (CLA): Good or bad trans fat? J. Food Comp. Anal. 22S, S4-S12

Park Y., Pariza, M.W., 2007. Mechanisms of body fat modulation by conjugated linoleic acid (CLA). Food Res. Int. 40, 311-323

Rayman M.P., 2004. The use of high-selenium yeast to raise selenium status: How does it measure up? Brit. J. Nutr. 92, 557-573

Statistica by StatSoft, 2002. Available at www.statssoft.pl

Tapiero H., Townsend D.M., Tew K.D., 2003. The antioxidant role of selenium and selenocompounds. Biomed. Pharmacotherapy 57, 134-144

Ulbricht T.L.V., Southgate D.A.T., 1991. Coronary heart disease: seven dietary factors. Lancet 338, 985-992

Walter F., 2004. Medical Physiology: A Cellular and Molecular Approach. Elsevier/Saunders. ISBN$1-4160-2328-3$

Weiss W.P., Hogan J.S., 2005. Effect of selenium source on selenium status, neutrophil function, and response to intramammary endotoxin challenge of dairy cows. J. Dairy Sci. 88, 4366-4374

Wysocka I.A., Bulska E., Wróbel K., 2003. A comparison of electrothermal atomic absorption spectrometry and inductively coupled plasma mass spectrometry for the determination of selenium in garlic. Chem. Anal. (Warsaw) 48, 919-929 